\title{
Seasonal changes in the diet of a critically endangered seabird and the importance of trawling discards
}

\author{
Joan Navarro • Maite Louzao · José Manuel Igual · Daniel Oro • \\ Antonio Delgado · José Manuel Arcos • Meritxell Genovart • \\ Keith A. Hobson • Manuela G. Forero
}

\begin{abstract}
Pelagic seabirds obtain food from oceans where the availability of their prey changes rapidly both seasonally and spatially. Here, we investigated changes in the trophic habits of the critically endangered Balearic shearwater (PuYnus mauretanicus) through the breeding season and tested for dietary diVerences between sexes and age classes. We analysed $\&^{15} \mathrm{~N}$ and $\&^{13} \mathrm{C}$ values in blood of adults during the pre-incubation, incubation and chick-rearing periods and of their chicks. Using a two-isotope mixing model, we estimated dietary contributions based on isotope values from potential prey species which included small pelagic
\end{abstract}

Communicated by R. Lewison.

J. Navarro (\&) • M. G. Forero

Department of Conservation Biology,

Estación Biológica de Doñana, CSIC,

Av. Américo Vespucio, s/n, 41092 Sevilla, Spain

e-mail: joan@ebd.csic.es

M. Louzao

Helmholtz Centre for Environmental Research-UFZ,

Permoserstraße 15, 04318 Leipzig, Germany

J. M. Igual · D. Oro · M. Genovart

Institut Mediterrani d'Estudis Avançats, IMEDEA (CSIC-UIB),

C/Miquel Marqués 21, 07190 Esporles, Mallorca, Spain

\begin{abstract}
A. Delgado
Estación Experimental del Zaidín, CSIC,

Profesor Albareda 1, Granada 18008, Spain
\end{abstract}

\section{J. M. Arcos}

Sociedad Española de Ornitología, SEO/BirdLife,

Delegación de Cataluña, C/Murcia 2, 08026 Barcelona, Spain

K. A. Hobson

Environment Canada, 11 Innovation Blvd.,

Saskatoon, SK S7N3H5, Canada species available naturally and demersal Wsh species available only from trawling discards. Balearic shearwaters showed clear isotopic and dietary variation through the breeding season. During pre-incubation, breeding adults appeared to exploit demersal Wsh, whereas during the incubation and chick-rearing period, they fed mainly on pelagic anchovies (Engraulis encrasicolus) and pilchards (Sardina pilchardus). Similarly, chicks were fed mainly with anchovies, a resource with a high energetic value. This variation in the dietary habits of adult shearwaters during the breeding season was probably related to both natural and Wsheryinduced seasonal changes in the availability of potential prey species within their main feeding grounds. However, changes in the nutritional requirements of the shearwaters could also play an important role. Indeed, diet diVered between sexes during pre-incubation: females fed less on trawling discards and more on small pelagic Wsh than males. This sexual segregation in diet could be the consequence of higher nutritional requirements of females during this period. Our study reveals the diVerential importance of both trawling discards and small pelagic Wsh species for a pelagic seabird depending on the breeding period and illustrates the importance of considering the entire breeding season when making inferences about the importance of speciWc prey in seabird dietary studies.

\section{Introduction}

Pelagic seabirds obtain their food from oceans where resources are patchily distributed and their abundance and availability changes seasonally (Brooke 2004). For this reason, their foraging eYciency and adaptation to these constraints are important components aVecting their population dynamics (Lewis et al. 2006). During the breeding season, 
when food demand is high, adult seabirds show Xexible feeding strategies, which help them cope with unpredictable prey availability and to cover nutritional requirements of reproduction (Brooke 2004). Beyond natural variability of prey, seabirds also face the impact of human activities such as commercial Wsheries. Fisheries can not only deplete marine Wsh stocks (Myers and Worm 2003) but also generate large volumes of discarded undersized Wshes and non-target species that several opportunistic seabirds have learned to exploit (i.e. Oro 1999; Tasker et al. 2000; Montevecchi 2002; Becker and Beissinger 2006).

This situation is especially true in the western Mediterranean ecosystem, where trawling discards have an impact on the foraging behaviour, breeding performance and population dynamics of opportunistic seabirds, including endangered species (Oro 1999; Arcos and Oro 2002a; Oro et al. 2004b; Louzao et al. 2006b). The Balearic shearwater (PuYnus mauretanicus) is one of the rarest seabirds in the world, currently listed as Critically Endangered by the IUCN (Oro et al. 2004a; BirdLife International 2008). The species is endemic to the western Mediterranean and about 2,200 breeding pairs breed in the Balearic Archipelago (BirdLife International 2008). During the breeding season, the species mainly forages over the eastern Iberian continental shelf (Louzao et al. 2006a), a highly productive and spawning area for small pelagic Wsh such as anchovies (Engraulis encrasicolus) and pilchards (Sardina pilchardus) and where important Wshing Xeets operate (Abad et al. 1998; Agostini and Bakun 2002; Palomera et al. 2007). Although the Balearic shearwater appears to primarily forage on shoals of small pelagic Wsh, mainly anchovies and pilchards, diVerent ecological models have also shown the importance of demersal and pelagic Wsh provided by trawling discards (Arcos and Oro 2002a; Abelló et al. 2003; Louzao et al. 2006b). Similarly, trawling discards also seem to improve the breeding performance of this and other endangered seabirds in the Mediterranean (Oro 1999; Louzao et al. 2006b). However, there are few data on the relative importance of both pelagic and demersal Wsh during the pre-laying and incubation period or on potential diVerences in diet related to sex or between adults and chicks.

Currently, the stable isotope approach can augment conventional means of dietary analysis since stable isotopes reXect time-integrated dietary records and thus eliminate some of the shortcomings of traditional dietary studies, particularly when used in combination with the stable isotope determination of potential prey (reviewed by Forero and Hobson 2003; Barrett et al. 2007). For a bird, the size of a shearwater, whole blood stable isotope values integrate dietary information over 3-4 weeks prior to sampling (Bearhop et al. 2002; Pearson et al. 2003). Thus, changes in dietary habits during the breeding season can be investigated by repeated blood sampling during breeding. Stable isotopes of nitrogen $\left(\&^{15} \mathrm{~N}\right)$ are indicators of trophic positions as consumers are predictably enriched in ${ }^{15} \mathrm{~N}$ relative to their food (Post 2002; Vanderklift and Ponsard 2003). Stable carbon isotope values $\left(\&^{13} \mathrm{C}\right)$ give information on primary production and are useful to trace origin of the prey consumed (Forero and Hobson 2003). Furthermore, combining stable isotope values of the consumers and their prey, isotopic mixing models can be applied to obtain estimates of the relative contribution of each potential prey to the diet habits of the consumer (Phillips and Gregg 2001).

Here, our main objective was to examine the trophic ecology of the Balearic shearwater throughout the breeding season. SpeciWcally, we investigated whether breeding shearwaters showed seasonal changes in diet and assessed whether there were age- (chicks vs. adults) and sex-related diVerences. Moreover, in order to disentangle the eVect of Wshing activity on the foraging ecology of shearwaters, we combined the analyses of $\&^{15} \mathrm{~N}$ and $\&^{13} \mathrm{C}$ values in blood of adults at diVerent breeding stages with those of their potential prey items, both naturally available pelagic species and trawling discards.

\section{Materials and methods}

\section{Fieldwork}

This study was conducted in 2003 in Sa Cella (Mallorca, Illes Balears, Spain, $39^{\circ} 30^{\prime} \mathrm{N}$; $2^{\circ} 33^{\prime} \mathrm{E}$, Fig. 1), a colony of about 200 breeding pairs of Balearic shearwater (Oro et al. 2004a). During the breeding period, we sampled individual males and females at pre-incubation (February), incubation (March-April) and chick-rearing (May-June) periods (see Table 1 for number of males and females sampled at each breeding stage). We also sampled chicks at the end of the chick-rearing period (mid June). From each bird, we took $0.1 \mathrm{ml}$ of blood that was preserved in $70 \%$ ethanol and further used for both molecular sexing and stable isotope analyses. We also collected samples of potential prey of shearwaters during May 2003 from an experimental oceanographic trawling cruise along the Iberian continental shelf (MEDITS-Mediterranean International Trawl Survey, Bertrand et al. 2002; Table 2). We focused on the Ebro Delta area because it is the main foraging ground for the Balearic shearwater during the breeding season (Arcos and Oro 2002a; Abelló et al. 2003; Louzao et al. 2006a). To select potential prey, we followed Arcos and Oro (2002a) who determined a feeding preference index for the Balearic shearwater selecting nine Wsh species and one cephalopod species commonly inhabiting the pelagic (4 species) and demersal sea compartment (6 species, Table 2). From each specimen, we sampled a muscle that was stored frozen at i $21^{\circ} \mathrm{C}$. 
Fig. 1 Location of the breeding colony (Sa Cella, Mallorca, Spain) and the main foraging ground (Ebro Delta area) for the Balearic shearwater, as well the location of the main trawling ports. The picture (courtesy of J. M. Arcos) shows a Balearic shearwater following a Wshing boat

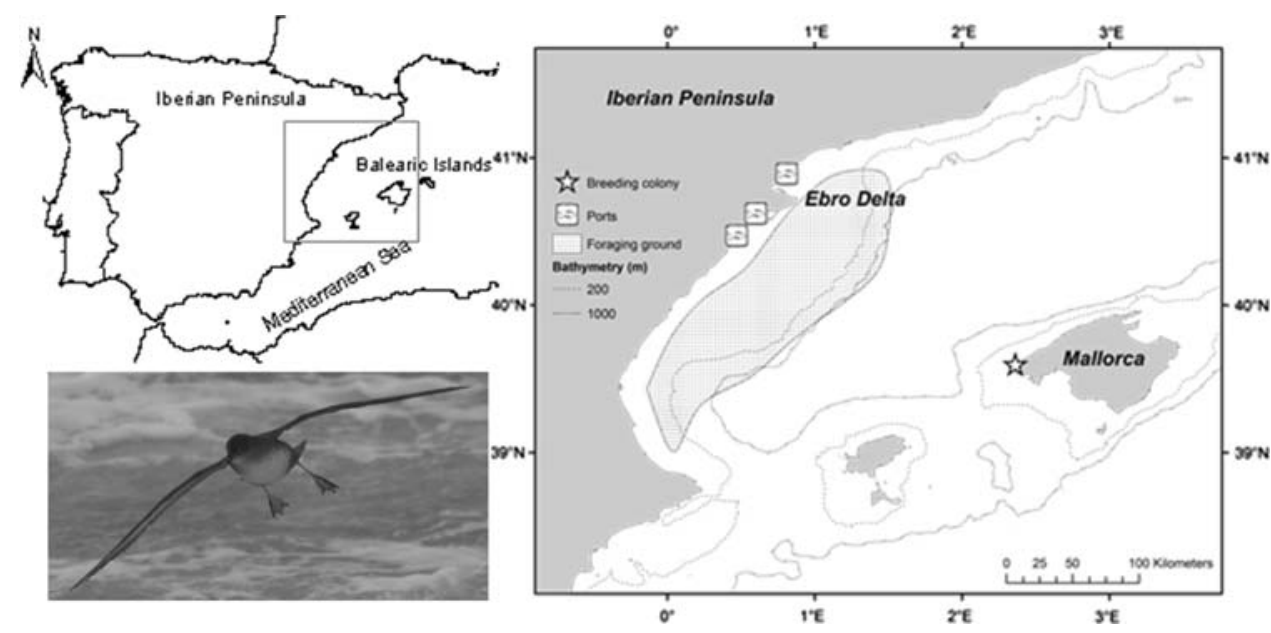

Table 1 Sample size $(n)$ and mean $\S$ standard deviation of $\&^{15} \mathrm{~N}$ and $\&^{13} \mathrm{C}$ values of Balearic shearwater throughout the breeding season

\begin{tabular}{|c|c|c|c|}
\hline & $n$ & $\&^{15} \mathrm{~N}(\% \circ)$ & $\&^{13} \mathrm{C}(\%)$ \\
\hline \multicolumn{4}{|l|}{ Adults } \\
\hline \multicolumn{4}{|c|}{ Pre-incubation } \\
\hline Males & 27 & $10.56 \S 0.52$ & i 17.69 \& 0.32 \\
\hline Females & 12 & $10.01 \S 0.76$ & i 17.99 § 0.25 \\
\hline \multicolumn{4}{|c|}{ Incubation } \\
\hline Males & 12 & $9.76 \S 0.57$ & i 18.86 § 0.40 \\
\hline Females & 9 & $10.12 \S 0.58$ & i 18.68 § 0.53 \\
\hline \multicolumn{4}{|c|}{ Chick rearing } \\
\hline Males & 27 & $10.51 \S 0.21$ & i 19.23 § 0.16 \\
\hline Females & 16 & $10.26 \S 0.32$ & i 19.35 § 0.23 \\
\hline \multicolumn{4}{|l|}{ Chicks } \\
\hline Males & 15 & $10.73 \S 0.24$ & i $20.01 \S 0.16$ \\
\hline Females & 27 & $10.51 \S 0.26$ & i 19.97 § 0.22 \\
\hline
\end{tabular}

Stable isotopes analyses

Ethanol was removed from blood samples prior to analysis by decanting and freeze-drying. For prey muscle, we removed two aliquots from each lyophilized muscle sample; one aliquot was immediately prepared for $\&^{15} \mathrm{~N}$ analysis. The other underwent lipid extraction prior to $\&^{13} \mathrm{C}$ analysis (Sholto-Douglas et al. 1991; Schlechtriem et al. 2003). Lipids were extracted using the methods of Smedes (1999). All samples (about 0.5-1 mg) were combusted at $1,020^{\circ} \mathrm{C}$ using continuous-Xow isotope-ratio mass spectrometry (CFIRMS) system by means of a Carlo Erba 1500NC elemental analyser interfaced with a Delta Plus XL mass spectrometer. All isotope abundances are expressed in \&-notation as parts per thousand (\%) deviation from the IAEA standards AIR $\left(\&^{15} \mathrm{~N}\right)$ and $\operatorname{VPDB}\left(\&^{13} \mathrm{C}\right)$. Based on within-run replicate measurements of lab standards (urea, shark cartilage), we estimated measurement error to be $\S 0.2$ and $\S 0.1 \%$ for $\&^{15} \mathrm{~N}$ and $\&^{13} \mathrm{C}$ values, respectively.

\section{Statistical analyses}

We tested the eVect of breeding stage (pre-incubation, incubation and chick rearing) and sex of adults on stable isotope values using analysis of variance (ANOVA). As segregation in the diet between sexes could change depending on the breeding stage, interaction between sex and breeding stage was also tested in the model. We tested the eVect of the age and sex of chicks (adults during chick rearing vs. male and female chicks) on stable isotope values by ANOVA. Similarly, we examined diVerences among prey groups using ANOVA. Post-hoc comparisons were tested with Tukey's test. Stable isotope values were previously log-transformed to meet normality. All statistical analyses were conducted by using SAS 9.1 software.

Isotope mixing model

Dietary composition of the Balearic shearwater at each breeding stage was estimated based on the isotopic values of potential prey. We created four diVerent prey groups according to the dietary importance of each prey species for the Balearic shearwater (Arcos and Oro 2002a): anchovies, pilchards, pelagic Wsh (Gadiculus argenteus and Micromesistius poutassou) and demersal species (Table 2). Statistical diVerences in stable isotope values among these prey groups were tested by an ANOVA and Tukey post-hoc comparisons). Because pilchards and pelagic Wsh did not diVer in their stable isotope values (see "Results"), we used only three clusters, anchovies, pelagic Wsh (including pilchards) and demersal Wsh, to further estimate the proportion of each potential prey consumed by the Balearic shearwater. We then created consumer end members for blood of shearwaters feeding exclusively on each of the 
Table 2 Sample size (n) and mean $\S$ standard deviation of $\&^{15} \mathrm{~N}$ and $\&^{13} \mathrm{C}$ values of the potential prey species for the Balearic shearwater, sampled in the Ebro Delta area (western Mediterranean) during spring 2003

Habitat type for each prey species is indicated ( $P$ pelagic, $D$ demersal) following FishBase (http://www.fishbase.org)

\begin{tabular}{llrrr}
\hline Species & Habitat & $n$ & \& $^{15} \mathrm{~N}(\%)$ & \& $^{13} \mathrm{C}(\%)$ \\
\hline Fish & & & & \\
Anchovy Engraulis encrasicolus & $\mathrm{P}$ & 10 & $8.85 \S 0.48$ & $\mathbf{i} 19.96 \S 0.46$ \\
Blue whiting Micromesistius poutassou & $\mathrm{P}$ & 10 & $8.90 \S 1.09$ & $\mathbf{i} 18.85 \S 0.86$ \\
Pilchard Sardina pilchardus & $\mathrm{P}$ & 10 & $7.24 \S 1.46$ & $\mathbf{i} 18.91 \S 0.71$ \\
Silvery cod Gadiculus argenteus & $\mathrm{P}$ & 9 & $6.81 \S 3.09$ & $\mathbf{i} 18.25 \S 0.37$ \\
Blotched picarel Spicara Xexuosa & $\mathrm{D}$ & 10 & $9.76 \S 0.73$ & $\mathbf{i} 19.31 \S 0.44$ \\
Brown comber Serranus hepatus & $\mathrm{D}$ & 9 & $10.68 \S 0.57$ & $\mathbf{i} 17.64 \S 0.47$ \\
Greater forkbeard Phycis blennoides & $\mathrm{D}$ & 10 & $8.65 \S 0.42$ & $\mathbf{i} 18.44 \S 0.15$ \\
Jewel lanternWsh Lampanyctus crocodilus & $\mathrm{D}$ & 8 & $7.57 \S 0.56$ & $\mathbf{i} 18.74 \S 0.45$ \\
Tonguesole Symphurus nigrescens & $\mathrm{D}$ & 8 & $11.41 \S 0.56$ & $\mathbf{i} 17.37 \S 0.29$ \\
Cephalopods & & & & $\mathbf{i} 17.62 \S 0.54$ \\
Common squid Alloteuthis subulata & $\mathrm{D}$ & 6 & $9.19 \S 1.61$ & \\
\hline
\end{tabular}

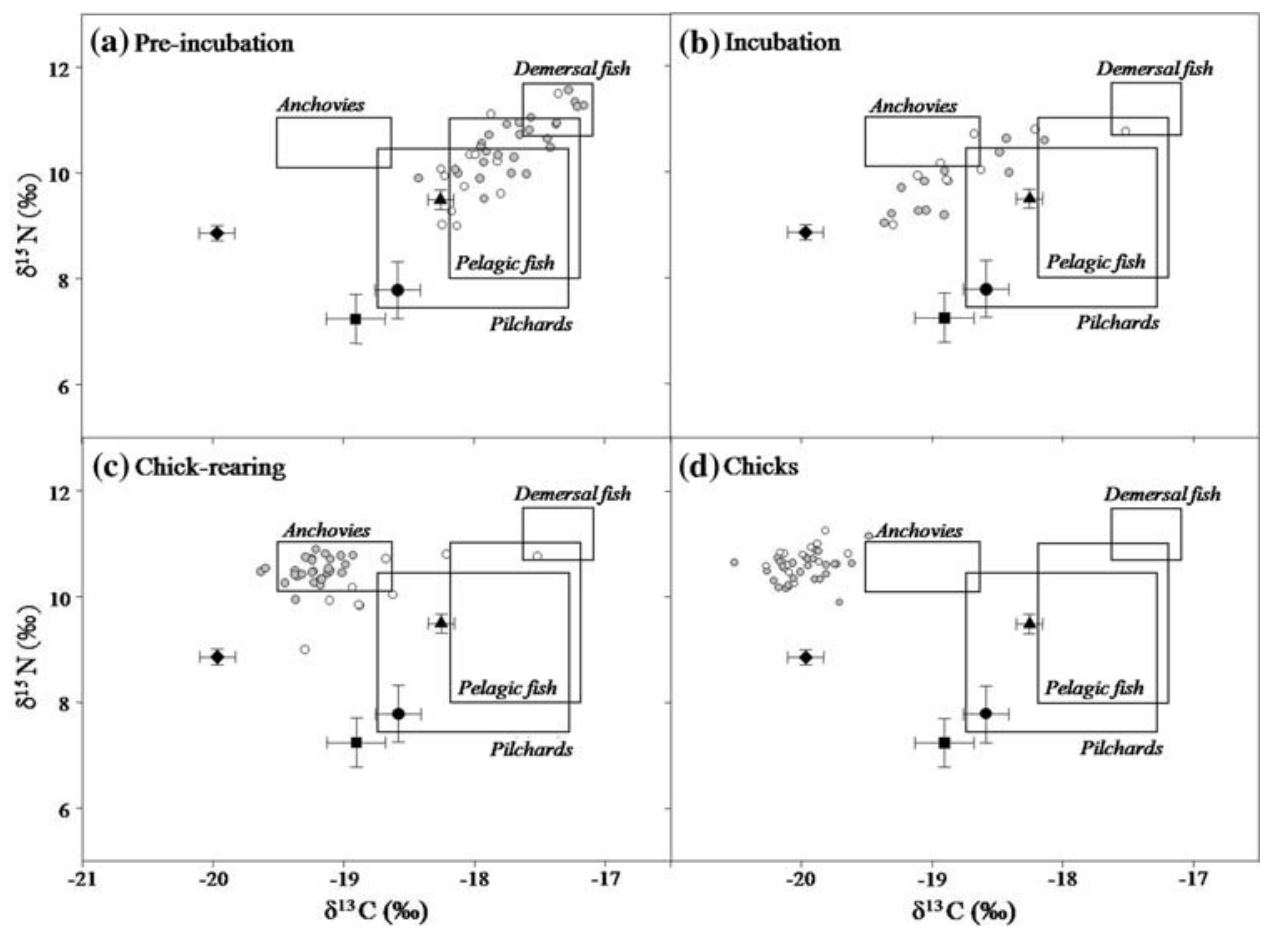

Fig. 2 Stable isotope values in blood $\left(\&^{15} N\right.$ and $\left.\&^{13} C\right)$ of breeding adults during pre-incubation (a), incubation (b), chick rearing (c) and chicks (d) of Balearic shearwater and their prey. White and grey circles indicate male and female shearwaters, respectively. Mean (SSE) of each group of potential prey items are indicated as follow: anchovies (Wlled diamond), pilchards (Wlled square), pelagic Wsh (Wlled circle, Gadiculus argenteus, Micromesistius poutassou) and demersal Wsh

three isotopically diVerent prey types (99\% CI, Fig. 2) using diet-blood isotopic fractionation values between prey muscle and whole blood of $1.7 \%$ for $\&^{15} \mathrm{~N}$ and $0.9 \%$ for $\&^{13} \mathrm{C}$. These values are derived from an isotopic study on the yellow-legged gull Larus michahellis from a breeding population that feed exclusively on pelagic Wsh (Ramos et al. 2009). We applied the Iso-Error dual-isotope, 3-source mixing model of Phillips and Gregg (2001).
(Wlled triangle, Serranus hepatus, Lampanyctus crocodilus, Spicara Xexuosa, Phycis blennoides, Symphurus nigrescens, and Alloteuthis subulata). Boxes represent the range of expected values in the consumer, considering 99\% CI for prey and accounting for diet-blood isotopic fractionation factors of $1.7 \%$ for $\&^{15} \mathrm{~N}$ and $0.9 \%$ for $\&^{13} \mathrm{C}$ (following Ramos et al. 2009). Partial labelling for expected dietary isotopic values (rectangular frames) is shown to enhance clarity

\section{Results}

Seasonal changes in stable isotope values in Balearic shearwater

Stable isotope values of Balearic shearwater varied depending of the breeding stage (Table 1). During incubation, breeding adults showed lower $\&^{15} \mathrm{~N}$ and higher $\&^{13} \mathrm{C}$ values 
Table 3 Summary of the ANOVA tests examining variation in stable isotopes between breeding stages for 66 males and 37 females Balearic shearwaters

\begin{tabular}{llrrl}
\hline Parameter & EVect & \multicolumn{1}{c}{$F_{[d f]}$} & \multicolumn{1}{l}{$P$} & Post-hoc \\
\hline$\&^{15} \mathrm{~N}(\%)$ & Sex & $5.86_{[1,102]}$ & 0.17 & \\
& Stage $£$ sex & $5.68_{[2,102]}$ & $<0.01$ & \\
& Stage & $5.86_{[2,102]}$ & $<0.01$ & I $x$ PI, CR \\
$\&^{13} \mathrm{C}(\%)$ & Sex & $1.56_{[1,102]}$ & 0.21 & \\
& Stage $£$ sex & $4.09_{[2,102]}$ & 0.02 & \\
& Stage & $208.13_{[2,102]}$ & $<0.001$ & PI $x$ I, CR \\
& & & & I $x$ CR \\
\hline
\end{tabular}

Symbols designating stage combination in Tukey post-hoc test summaries are: $P I$ pre-incubation; $I$ incubation; $C R$ chick rearing. Pairs of means diVering signiWcantly $(P=0.05)$ by Tukey test are linked with an ' $x$ '

than during pre-incubation and chick rearing (Table 1, and see post-hoc comparison in Table 3). Although we did not detect a signiWcant eVect of sex throughout breeding on $\&^{15} \mathrm{~N}$ and $\&^{13} \mathrm{C}$ isotopic values (Table 3 ), males showed higher $\&^{15} \mathrm{~N}$ values than females during the pre-incubation (Table 1. $T=2.48, d f=76, P=0.01$ ). Male chicks had higher $\&^{15} \mathrm{~N}$ values than female chicks (Table $1, T=2.55$, $d f=42, \quad P=0.01$ ), whereas $\&^{13} \mathrm{C}$ values did not diVer between male and female chicks (Table $1, T=\mathbf{i} 0.56$, $d f=42, P=0.57)$. During the chick-rearing period, adults had lower $\&^{15} \mathrm{~N}$ (adults vs. male chicks: $T=3.77, d f=56$, $P<0.001$; adults vs. female chicks: $T=2.55, d f=40$, $P=0.01$ ) and higher $\&{ }^{13} \mathrm{C}$ values than chicks (adults vs. male chicks: $T=$ i 12.63, $d f=56, P<0.001$; adults vs. female chicks: $T=$ i $0.56, d f=40, P=0.57$; Table 1 ).

Isotopic values of potential prey

Overall, both $\&^{15} \mathrm{~N}$ and $\&^{13} \mathrm{C}$ values diVered among the four prey groups (Table 2; Fig. 2. For $\&^{15} \mathrm{~N} ; \quad F_{2,97}=9.74$, $P<0.0001$. For $\&^{13} C ; F_{2,97}=17.85, P<0.0001$ ). Demersal species showed higher $\&^{15} \mathrm{~N}$ values than pilchards and pelagic Wsh, and similar values as anchovies (Table 2; Fig. 2. Tukey test, $P<0.0001,<0.0001$ and $=0.61$, respectively). Concerning $\&^{13} \mathrm{C}$ values, anchovies had lower values than demersal species, pilchards and pelagic Wsh (Table 2; Fig. 2, Tukey test, $P<0.0001,0.0001$ and 0.001, respectively). Only pelagic Wsh and pilchards had similar $\&^{15} \mathrm{~N}$ and $\&^{13} \mathrm{C}$ values (Table 2; Fig. $2, P=0.67$ and 0.81 , respectively).

Dietary changes during breeding season inferred by isotopic mixing model

The proportion of each prey type in the diet of the Balearic shearwater changed throughout the breeding season

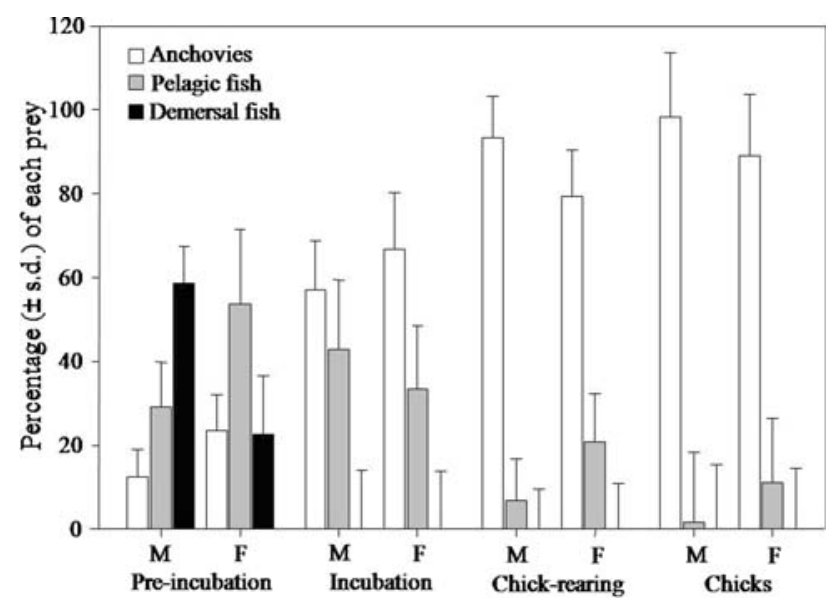

Fig. 3 Results of the Iso-Error mixing model (Phillips and Gregg 2001) for the percentage (mean $\$$ SD) of each prey group in the diet of male and female Balearic shearwaters during the diVerent breeding stages. The potential groups were; anchovies, pelagic Wsh (Gadiculus argenteus, Micromesistius poutassou, and Sardina pilchardus) and demersal Wsh (see Table 2)

(Fig. 3). During the pre-incubation period, the diet of adult males was composed mostly of demersal Wsh (58.5 § 8.9\%), followed of pelagic Wsh (29.0 § 10.8\%) and then anchovies (12.4 § 6.7). In contrast, the diet of females during pre-incubation was composed mainly of pelagic Wsh (53.8 § 17.8\%), followed by anchovies and demersal Wsh in a similar proportion (23.6 § 8.4 and 22.6 § 13.9\%, respectively). During incubation (Fig. 3), the model estimated that the diet of males and females was composed mainly of anchovies (57.1 § 11.7 and 66.6 § 13.6\%, respectively) and pelagic Wsh (42.0 § 16.5 and 33.8 § $15.2 \%$, respectively), whereas demersal Wsh were not present. During chick rearing, both sexes fed mainly on anchovy (males $=93.2 \S 10.1 \%$, females $=79.3 \S 11.1 \%$ ) and secondly on pelagic Wsh (less than 15\%) and demersal species were not consumed. Finally, the model indicated that adults fed their male and female chicks mainly with anchovies (98.3 § 15.3 and 88.9 § 14.7\%, respectively), and in much lower proportion with pelagic Wsh (1.7 § 16.6 and $11.0 § 15.3 \%)$.

\section{Discussion}

Stable isotope analyses revealed clear changes in the diet of the Balearic shearwater throughout the breeding season, and a subtler, apparent diVerence in the diet between males and females during the pre-incubation period. This variation in diet was probably related to complex interrelationships aVecting natural- and Wshery-induced seasonal changes in the availability of their potential prey and to nutritional requirements during reproduction. These results 
illustrate the importance of considering the entire breeding season when conducting studies of trophic ecology of seabirds.

It is well documented that Wshing activity provides substantial food for opportunistic seabirds through the discarding of non-target demersal and pelagic species (e.g. Oro 1999; Furness and Tasker 2000; Tasker et al. 2000; Arcos and Oro 2002b; Votier et al. 2004). Similar to previous studies, we found that Balearic shearwaters clearly exploited this artiWcial resource during the breeding period, but were able to provide a quantitative estimate of the relative importance of this resource during the breeding season. During pre-incubation, breeding adults fed on demersal species, prey only available for surface feeders such as the Balearic shearwater through trawling discards (Arcos et al. 2008). Breeding shearwaters probably also obtained some of their pelagic Wsh and anchovies from the trawling discards in addition to natural-foraging behaviours since they can become available in addition to demersal species during Wshing operations at the Ebro Delta (Arcos and Oro 2002a, b; Louzao et al. 2006b).

So, why did breeding shearwaters apparently only feed on demersal species during pre-incubation? In the north eastern Iberian shelf, the main feeding area for Balearic shearwaters (Louzao et al. 2006a), the abundance of anchovies and pilchards changes seasonally during the year, showing lower abundances between FebruaryMarch, coinciding with the pre-incubation period of Balearic shearwater (Lloret et al. 2004). Therefore, breeding birds probably included demersal species in their diet because they were relatively more available during this period. During April-June, coinciding with the incubation and chick-rearing period of the Balearic shearwater, the abundance of anchovies and pilchards in the Ebro Delta is higher than during the pre-incubation period (Lloret et al. 2004), supporting the hypothesis that breeding adults exploit the most available resource within their feeding ground. Moreover, the exploitation of anchovies and other pelagic Wsh (including pilchards) might help birds meet the high energetic requirements of breeding due to their high energetic content (Arcos and Oro 2002a; Grémillet et al. 2008). For instance, adults fed their chicks mainly with anchovies, a high energetic prey item (Arcos and Oro 2002a; Grémillet et al. 2008). Although both chicks and rearing adult shearwaters apparently consumed the same trophic resources, we found that chicks showed higher $\&^{15} \mathrm{~N}$ values than adults rearing chicks. This isotopic diVerence could be related to physiological eVects related to the chick-growing process. Because chicks are growing, their increase in catabolism of protein stores could result in increases in $\&^{15} \mathrm{~N}$ values (Navarro et al. 2007; Williams et al. 2007).
On the other hand, the lower $\&^{13} \mathrm{C}$ values of chicks compared with adults could be related to the high lipid reserves of the chicks that could depleted their blood $\&^{13} \mathrm{C}$ values (Phillips and Hamer 1999; Thompson et al. 2000; Williams et al. 2007).

The dietary habits of male and female shearwaters diVered during the pre-incubation period; females fed less on demersal Wsh than males and consumed a higher proportion of anchovies and pelagic Wsh. This sexual segregation in diet could be the consequence of diVerential nutritional requirements of males and females during preincubation relating to the egg formation (Williams 2005). In general, the nutritional value of demersal species in terms of lipids and proteins is lower than pelagic species (Arcos and Oro 2002a; Grémillet et al. 2008). For this reason, females, constrained by egg formation, probably need to feed on species of higher nutritional content (Grémillet et al. 2008). Previous studies suggested a positive relationship between hatching success and the availability of pelagic Wsh (Louzao et al. 2006b), and between egg size and trophic level of Balearic shearwaters (Louzao et al. 2008).

In conclusion, this study illustrates and reinforces the importance of both pelagic and demersal Wsh as trophic resources for the Balearic shearwater during the breeding period (Arcos and Oro 2002a, b; Louzao et al. 2006b; Arcos et al. 2008). During pre-incubation, when the natural abundance of prey of high-energy content such as anchovy and pilchards was low, breeding shearwaters exploited demersal Wsh species, an artiWcial resource only available for the shearwaters through trawling discards. Later, during incubation and chick rearing, the diet of both adults and chicks was composed exclusively of anchovies and pelagic Wsh, probably related to their higher natural abundance and their higher energetic contents. Furthermore, female shearwaters showed clearly diVerent trophic habits than males during pre-incubation, female shearwaters consumed less demersal Wsh and more pelagic Wsh species than male shearwaters during the pre-incubation probably linked to the egg formation requirements. Even though trawling discards represent a additional and easy (due to their predictability in space and time) foraging resource for shearwaters and the potential Wtness -and conservation- beneWts for birds, it is important to consider discards as an undesirable oVset of a non-selective, damaging human activity for marine ecosystems, and thus a phenomenon to be eradicated in the near future.

Acknowledgments We extend thanks to Isabel Afán and to Arsenio Granados for their Weldwork and stable isotope analyses, respectively. Fish samples were collected within the frame of the MEDITS project, with the help of Luis Gil de Sola, Pere Abelló and the scientists and crew at R/V Cornide de Saavedra (Spanish Institute of Oceanography, IEO). Research funds were provided by several grants from the Spanish 
Government (P06-RNM-02362, REN2002-00450, BOS2003-01960 and CGL2006-04325/BOS). Maite Louzao was supported by a $\mathrm{PhD}$ fellowship of the Balearic Government and a post-doctoral fellowship of the Spanish Ministry of Education and Science (Ref. EX-20071148). Meritxel Genovart was funded by an I3P post-doctoral fellowship from the Spanish Ministry of Education and Science. Four referees contributed to improve a previous draft.

\section{References}

Abad R, Miquel J, Iglesias M, Álvarez F (1998) Acoustic estimation of abundance and distribution of anchovy in the NW Mediterranean. Sci Mar 62:37-43

Abelló P, Arcos JM, Gil de Sola L (2003) Geographical patterns of seabird attendance to a research trawler along the Iberian Mediterranean coast. Sci Mar 67:69-75

Agostini VN, Bakun A (2002) 'Ocean triads' in the Mediterranean Sea: physical mechanisms potentially structuring reproductive habitat suitability (with example application to European anchovy, Engraulis encrasicolus). Fish Oceanogr 11:129-142

Arcos JM, Oro D (2002a) SigniWcance of Wsheries discards for a threatened Mediterranean seabird, the Balearic shearwater PuYnus mauretanicus. Mar Ecol Prog Ser 239:209-220

Arcos JM, Oro D (2002b) SigniWcance of nocturnal purse seine Wsheries for seabirds: a case study oV the Ebro Delta (NW Mediterranean). Mar Biol 141:277-286

Arcos JM, Louzao M, Oro D (2008) Ecosystem impacts and management in the Mediterranean: seabirds point of view. In: Nielsen JL, Dodson JJ, Friedland K, Hamon TR, Musick J, Verspoor E (eds) Reconciling Wsheries with conservation: proceedings of the Fourth World Fisheries Congress. American Fisheries Society, Symposium 49. Bethesda, pp 1471-1479

Barrett RT, Camphuysen KCJ, Anker-Nilssen T, Chardine JW, Furness RW, Garthe S, Hüppop O, Leopold MF, Montevecchi WA, Veit RR (2007) Diet studies of seabirds: a review and recommendations. ICES J Mar Sci 64:1675-1691

Bearhop S, Waldron S, Votier SC, Furness RW (2002) Factors that inXuence assimilation rates and fractionation of nitrogen and carbon stable isotopes in avian blood and feathers. Physiol Biochem Zool 75:451-458

Becker BH, Beissinger SR (2006) Centennial decline in the trophic level of an endangered seabird after Wsheries decline. Conserv Biol 20:470-479

Bertrand JA, Gil de Sola L, Papaconstantinou C, Relini G, Souplet A (2002) The general speciWcations of the MEDIS surveys. Sci Mar 66:9-17

BirdLife International (2008) PuYnus mauretanicus. IUCN 2008. 2008 IUCN Red List of Threatened Species

Brooke M (2004) Albatrosses and petrels across the world. Oxford University Press, Oxford

Forero MG, Hobson KA (2003) Using stable isotopes of nitrogen and carbon to study seabird ecology: applications in the Mediterranean seabird community. Sci Mar 67:23-32

Furness RW, Tasker ML (2000) Seabird-Wshery interactions: quantifying the sensitivity of seabirds to reductions in sandeel abundance, and identiWcation of key areas for sensitive seabirds in the North Sea. Mar Ecol Prog Ser 202:253-264

Grémillet D, Pichegru L, Kuntz G, Woakes AG, Wilkinson S, Crawford RJM, Ryan PG (2008) A junk-food hypothesis for gannets feeding on Wshery waste. Proc R Soc B 275:1149_ 1156

Lewis S, Grémillet D, Daunt F, Ryan P, Crawford RJM, Wanless S (2006) Using behavioural variables to identify proximate causes of population change in a seabird. Oecologia 147:606-614
Lloret J, Palomera I, Salat J, Sole I (2004) Impact of freshwater input and wind on landings of anchovy (Engraulis encrasicolus) and sardine (Sardina pilchardus) in shelf waters surrounding the Ebre (Ebro) River delta (north-western Mediterranean). Fish Oceanogr 13:102-110

Louzao M, Hyrenbach KD, Arcos JM, Abelló P, de Sola LG, Oro D (2006a) Oceanographic habitat of an endangered Mediterranean procellariiform: implications for marine protected areas. Ecol Aplic 16:1683-1695

Louzao M, Igual JM, McMinn M, Aguilar JS, Triay R, Oro D (2006b) Small pelagic Wsh, trawling discards and breeding performance of the critically endangered Balearic shearwater: improving conservation diagnosis. Mar Ecol Prog Ser 318:247-254

Louzao M, Igual JM, Genovart M, Forero MG, Hobson KA, Oro D (2008) Spatial variation in egg size of a top predator: interplay of body size and environmental factors? Acta Oecol 34:186-193

Montevecchi WA (2002) Interactions between Wsheries and seabirds. In: Schreiber EA, Burger J (eds) Biology of marine birds. CRC Press, Boca Raton, pp 527-557

Myers RA, Worm B (2003) Rapid worldwide depletion of predatory Wsh communities. Nature 423:280-283

Navarro J, González-Solís J, Viscor G (2007) Nutritional and feeding ecology in the Cory's shearwater (Calonectris diomedea) during breeding. Mar Ecol Prog Ser 351:261-271

Oro D (1999) Trawler discards: a threat or a resource for opportunistic seabirds? In: Adams NJ, Slotow RH (eds) Proceedings 22 International Ornithol Congress Durban. BirdLife South Africa, Johannesburg, pp 717-730

Oro D, Aguilar JS, Igual JM, Louzao M (2004a) Modelling demography and extinction risk in the endangered Balearic shearwater. Biol Conserv 116:93-102

Oro D, Cam E, Pradel R, Martínez-Abraín A (2004b) InXuence of food availability on demography and local population dynamics in a long-lived seabird. Proc R Soc B 271:387-396

Palomera I, Olivar MP, Salat J, Sabatés A, Coll M, Gracía A, MoralesNin B (2007) Small pelagic Wsh in the NW Mediterranean Sea: an ecological review. Prog Ocean 74:37-396

Pearson SF, Levey DJ, Greenberg CH, Martínez del Rio C (2003) EVects of elemental composition on the incorporation of dietary nitrogen and carbon isotopic signatures in an omnivorous songbird. Oecologia 135:516-523

Phillips DL, Gregg JW (2001) Uncertainty in source partitioning using stable isotopes. Oecologia 127:171-179

Phillips RA, Hamer KC (1999) Lipid reserves, fasting capability and the evolution of nestling obesity in procellariiform seabirds. Proc R Soc B 266:1329-1334

Post DM (2002) Using stable isotopes to estimate trophic position: models, methods, and assumptions. Ecology 83:703-718

Ramos R, Ramírez F, Sanpera C, Jover L, Ruiz X (2009) Feeding ecology of yellow-legged gulls (Larus michahellis) in the western Mediterranean: a comparative assessment using conventional and isotopic methods. Mar Ecol Prog Ser 377:289-297

Schlechtriem CH, Focken U, Becker K (2003) EVect of diVerent lipid extraction methods on d13c of lipid and lipid-free fractions of Wsh and diVerent Wsh feeds. Isot Environ Health Stud 39:135140

Sholto-Douglas AD, Field JG, James AG, Merwe NJ (1991) ${ }^{13} \mathrm{C} /{ }^{12} \mathrm{C}$ and ${ }^{15} \mathrm{~N} /{ }^{14} \mathrm{~N}$ isotope ratios in the Southern Benguela Ecosystem: indicators of food web relationships among diVerent size-classes of plankton and pelagic Wsh; diVerences between Wsh muscle and bone collagen tissues. Mar Ecol Prog Ser 78:23-31

Smedes F (1999) Determination of total lipid using non-chlorinated solvents. Analyst 124:1711-1718

Tasker ML, Camphuysen CJ, Cooper J, Garthe S, Montevecchi WA, Blaber SJM (2000) The impacts of Wshing on marine birds. ICES J Mar Sci 57:531-547 
Thompson DR, Phillips RA, Stewart FM, Waldron S (2000) Low d ${ }^{13} \mathrm{C}$ signatures in pelagic seabirds: lipid ingestion as a potential source of ${ }^{13} \mathrm{C}$-depleted carbon in the Procellariiformes. Mar Ecol Prog Ser 208:265-271

Vanderklift MA, Ponsard S (2003) Sources of variation in a consumer-diet $\mathrm{d}^{15} \mathrm{~N}$ enrichment: a meta-analysis. Oecologia 136:169-182

Votier SC, Furness RW, Bearhop S, Crane JE, Caldow RWG, Catry P, Ensor K, Hamer KC, Hudson AV, Kalmbach E, Klomp NI,
PfeiVer S, Phillips RA, Prieto I, Thompson DR (2004) Changes in Wsheries discard rates and seabird communities. Nature 427:727-730

Williams TD (2005) Mechanisms underlying the costs of egg production. Bioscience 55:39-48

Williams CT, Buck CL, Sears J, Kitaysky AS (2007) EVects of nutritional restriction on nitrogen and carbon stable isotopes in growing seabirds. Oecologia 153:11-18 